\title{
Left atrial strain - an early marker of left ventricular diastolic dysfunction in patients with hypertension and paroxysmal atrial fibrillation
}

\author{
Jonas Jarasunas* (iD, Audrius Aidietis and Sigita Aidietiene
}

\begin{abstract}
Background: 2D strain imaging of the left atrium $(L A)$ is a new echocardiographic method which allows us to determine contractile, conduit and reservoir functions separately. This method is particularly useful when changes are subtle and not easily determined by traditional parameters, as it is in arterial hypertension and atrial fibrillation (AF). The aims of our study were: to determine LA contractile, conduit and reservoir function by 2D strain imaging in patients with mild arterial hypertension and paroxysmal AF; to assess LA contractile, conduit and reservoir functions' relation with LV diastolic dysfunction (DD) parameters.

Methods: LA contractile, conduit and reservoir functions together with echocardiographic signs of LV DD were assessed in 63 patients with arterial hypertension and paroxysmal AF. Patients were grouped according to number of signs showing LV DD (annular e' velocity: septal $e^{\prime}<7 \mathrm{~cm} / \mathrm{s}$, lateral $e^{\prime}<10 \mathrm{~cm} / \mathrm{s}$, average E/e' ratio $>14$, LA volume index $>34 \mathrm{ml} / \mathrm{m}^{2}$, peak tricuspid regurgitation velocity $>2.8 \mathrm{~m} / \mathrm{s}$ ) present. Number of patients with 0 signs - 17, 1 sign - 26, 2 signs - 19. Contractile, conduit and reservoir functions were compared between the groups.

Results: Mean contractile, conduit and reservoir strains in all the patients were $-14.14( \pm 5.83) \%, 15.98( \pm 4.85) \%$ and $31.03( \pm 7.64) \%$ respectively. Contractile strain did not differ between the groups. Conduit strain was higher in patients with 0 signs compared with other groups ( $p=0.016$ vs 1 sign of LV DD and $p=0.001$ vs 2 signs of LV DD). Reservoir strain was higher in patients with 0 signs compared with other groups ( $p=0.014$ vs 1 sign of LV DD and $p<0.001$ vs 2 signs of LV DD).

Conclusions: The patients with paroxysmal AF and primary arterial hypertension have decreased reservoir, conduit and pump LA functions even in the absence of echocardiographic signs of LV DD. With increasing number of parameters showing LV DD, LA conduit and reservoir functions decrease while contractile does not change. LA conduit and reservoir functions decrease earlier than the diagnosis of LV DD can be established according to the guidelines in patients with primary arterial hypertension and AF.
\end{abstract}

Keywords: Left atrial strain, Diastolic dysfunction, Arterial hypertension, Atrial fibrillation

\footnotetext{
* Correspondence: jonasjar@gmail.com

Clinic of Cardiac and Vascular Diseases, Institute of Clinical Medicine, Faculty

of Medicine, Vilnius University, Universiteto g. 3, LT-01513 Vilnius, Lithuania
}

(c) The Author(s). 2018 Open Access This article is distributed under the terms of the Creative Commons Attribution 4.0 International License (http://creativecommons.org/licenses/by/4.0/), which permits unrestricted use, distribution, and reproduction in any medium, provided you give appropriate credit to the original author(s) and the source, provide a link to the Creative Commons license, and indicate if changes were made. The Creative Commons Public Domain Dedication waiver (http://creativecommons.org/publicdomain/zero/1.0/) applies to the data made available in this article, unless otherwise stated. 


\section{Background}

Traditionally the greatest attention during a routine echocardiography is paid to the function of the ventricles and assessment of the atria is limited to measuring the dimensions and volumes of the chambers. Though assessing ventricular function is essential, there is robust data that atrial function is also important and can improve our decision making by determining the risk of cardiovascular events in various conditions [1]. Hypertension is the most common predisposing factor for left ventricular (LV) diastolic dysfunction (DD), which leads to increased left atrial (LA) pressure, its enlargement and fibrosis as well as other proarrhythmic pathological effects on atrial structure and function [2, 3]. These changes cause various cardiac arrhythmias, most commonly atrial fibrillation (AF), an arrhythmia that carries a substantial risk of embolic events. Hypertension and even high-normal blood pressure is a risk factor for developing $\mathrm{AF}$ and recent guidelines for the management of arterial hypertension clearly state that AF should be considered a manifestation of hypertensive heart disease [4]. LA function might also be linked to the cardioembolic risk profile in patients with AF and can even provide incremental value for embolism risk stratification over CHA2DS2-VASc score [5, 6]. Recently announced EACVI AFib Echo Europe Registry for assessing relationships of echocardiographic parameters with clinical thrombo-embolic and bleeding risk profile in non-valvular AF aims to determine echocardiographic parameters stratifying prognosis and improving management in categories of AF patients. In this regard LA parameters are among the most promising ones [7].

There are many well established and validated methods to assess left and right ventricular function but the ones for assessing atrial function are lacking. Speckle tracking echocardiography has proven to be useful and applicable not only in the assessment of LV wall motion abnormalities but also in the assessment of LA function. Though the method is more and more studied it is still not widely used in daily clinical practice primarily because there are still some methodological and standardization issues which need to be addressed. The question of normal values is also still valid, though metanalysis by Faraz Pathan et al. was a real step forward in determining normal ranges [8].

One of the most promising areas the method can be used in is hypertension where the LA and LV dysfunctions occuring early in the course of disease can be subtle and not easily determined by traditional echocardiographic parameters [9]. 2D strain parameters of the LA can help to detect increased filling pressures and DD of the LV earlier [10], and, which is very important, antihypertensive treatment can reverse these changes [11].
The aims of our study were: a) to determine LA contractile, conduit and reservoir function by 2D strain imaging in patients with mild arterial hypertension and paroxysmal atrial fibrillation; b) to assess LA contractile, conduit and reservoir functions' relation with LV filling pressure parameters recommended by the American Society of Echocardiography and the European Association of Cardiovascular Imaging [12].

\section{Methods}

We assessed 63 patients aged 18-80 with I or II grade primary arterial hypertension and at least one ECG confirmed episode of paroxysmal AF within last year. Only the patients that were in sinus rhythm at the time of investigation were included in the study. Patients with other known causes of AF such as heart failure, coronary heart disease, prior heart surgery, structural heart disease, reduced LV ejection fraction, thyroid dysfunction (assessed by thyroid-stimulating hormone concentration) or renal failure with glomerular filtration rate $<60 \mathrm{ml} /$ min were excluded from the study. Only the ones with hypertension as a possible causative factor for AF were included in the study.

Physical examination, including weight and height was performed. All patients underwent ambulatory blood pressure monitoring, which was carried out according to European Society of Hypertension guidelines [13]. A Meditech $\operatorname{card}(\mathrm{X})$ plore monitor and CardioVisions 1.23.0 software were used. The measurements were taken in 20-min intervals during the day and in 40-min intervals during the night. The patients who did not meet the $70 \%$ successful measurement criterion were excluded from the analysis.

All the patients had an ECG and sonography of the heart done. Only the ones with acceptable ultrasound image quality were included in the final analysis. A GE Vivid E9 system was used for ultrasound imaging in our study. Routine sonographic examination of the heart was performed as described in the American and European Society of Echocardiography guidelines and their update [14-16] with a cardiac probe M5S-D.

The thicknesses of the interventricular septal and the inferolateral walls as well as LV end-diastolic and end-systolic diameters were obtained from the parasternal short-axis view. LV mass (LVM) was calculated using linear method as recommended in the update Recommendations for cardiac chamber quantification by echocardiography in adults [16]. Cube formula was used:

$$
\begin{aligned}
\mathrm{LVM} & =0.8 \times 1.04\left[(\mathrm{LVEDd}+\mathrm{PWDd}+\mathrm{IVSDd})^{3}-\mathrm{LVEDd}^{3}\right] \\
& +0.6 \mathrm{~g}
\end{aligned}
$$

where LVEDd is LV end-diastolic internal diameter; PWDd, diastolic posterior wall thickness; and IVSTd, diastolic interventricular septal thickness. To determine 
LV hypertrophy LVM was subsequently indexed to body surface area BSA (calculated using DuBois formula). Two waves (E and $A$ ) of mitral inflow velocity were recorded using pulsed wave Doppler from the apical 4 chamber view. The velocity waves (e' and a') of mitral annulus septal and lateral regions were recorded using tissue Doppler. When calculating E/e' ratio, an average value of septal and lateral mitral annulus velocities was used.

LV and LA volumes were determined using the biplane disk summation technique from apical 4-chamber and 2 -chamber views. LV end systolic and end diastolic volume was recorded, then LV ejection fraction was calculated using these measurements.

Global longitudinal 2D LA strain was analyzed by the speckle tracking technique using GE EchoPAC software. The images were acquired according to the recommendations given by expert consensus statement published in the European Journal of Echocardiography [17]. For analysis we used four-chamber and two chamber apical view images of LA carefully avoiding foreshortening. The focus was set to the level of mid-LA to optimize the image quality. Sector depth and width was adjusted to include as little as possible outside the region of interest. Three consecutive heart cycles were recorded during a single breath hold using a frame rate of $>80$ frames/second for offline analysis. The endocardial border of LA was manually traced and a region of interest was manually adjusted to include the entire LA wall thickness. The software selected stable speckles within the LA wall and tracked these speckles frame-by-frame throughout the cardiac cycle. The entire LA tracking was then divided into 6 segments by the software and tracking quality for each segment was provided. If the tracking was not acceptable, endocardial borders were readjusted until better tracking was achieved. Then, we set the starting point of strain analysis as $\mathrm{P}$-wave onset instead the software preset $\mathrm{R}$-wave peak. The automated software then generated traces depicting the regional longitudinal strain for each segment and calculated global longitudinal strain. Using $\mathrm{P}$ wave onset as starting enabled us to define first negative peak, which occurred at maximal LA contraction and represented its contractile function (contractile strain), first positive peak, which occurred at mitral valve opening and represented LA conduit function (conduit strain), and the difference of these peaks, which represented reservoir function (reservoir strain). The values were averaged for all 12 LA segments - 6 in apical four chamber view and 6 in apical two chamber view. LA strain image from four-chamber apical view is shown in Fig. 1. Analogous measurements were performed from apical two-chamber views.

LV diastolic function and filing pressures were evaluated according to the American Society of Echocardiography and the European Association of Cardiovascular Imaging recommendations published in 2016 [12]. The patients were grouped as having none, one, two or three signs of LV DD, according to the guidelines. The variables for identifying LV DD and their cutoffs were annular e' velocity: septal e' $<7 \mathrm{~cm} / \mathrm{s}$, lateral $\mathrm{e}^{\prime}<10 \mathrm{~cm} / \mathrm{s}$,

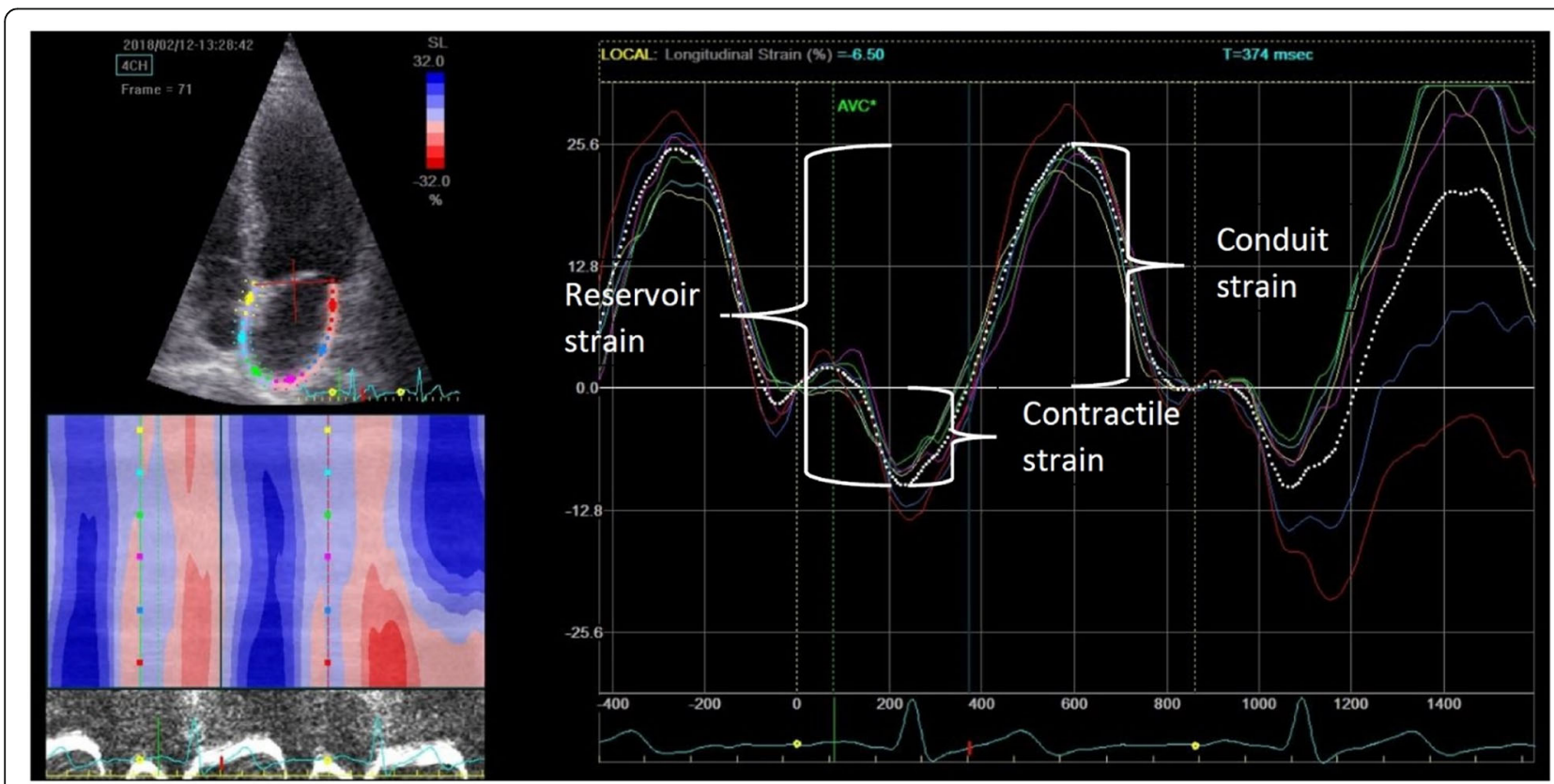

Fig. $12 D$ LA strain image from four-chamber apical view. Setting the starting point of strain analysis at the beginning of the $p$ wave on the ECG allowed us to define first negative peak, first positive peak and the difference of these peaks which corresponded to atrial contractile strain, conduit strain and reservoir strain respectively 
average $\mathrm{E} / \mathrm{e}^{\prime}$ ratio $>14$, LA volume index $>34 \mathrm{ml} / \mathrm{m}^{2}$, peak tricuspid regurgitation velocity $>2.8 \mathrm{~m} / \mathrm{s}$.

The intra- and interobserver variability of contractile, conduit and reservoir LA strains was assessed in 20 randomly selected patients. Intraobserver variability was performed by the same echocardiographer blinded to previous measurements and interobserver variability was performed by a second experienced echocardiographer also blinded to previous measurements. The intraclass correlation coefficient together with the absolute difference divided by the mean of two measurements and given as a percentage were calculated for both intra- and interobserver variability.

For statistical analysis Microsoft Excel and SPSS Statistics 17.0 software was used. The mean values are presented \pm standard deviation (SD) or 95\% confidence intervals (CI). Shapiro-Wilk test was used to check if the distribution of the data was normal. The means were compared using ANOVA and Fisher's Least Significant Difference test was used for post hoc analysis. Pearson's correlation coefficient was used to test for correlation. $P$ value of $<0.05$ was considered significant.

\section{Results}

Sixty-three patients who met inclusion/exclusion criteria, had acceptable ultrasound picture quality and signed informed consent were included in the final analysis. The patients' demographic, physical examination and blood pressure data is presented in Table 1. Ultrasound of the heart data is presented in Table 2. Intraclass correlation coefficients $(95 \% \mathrm{CI})$ for intraobserver variability of LA contractile, conduit and reservoir strains were $0.91(0.79-0.96), 0.92(0.81-0.97)$ and 0.94 $(0.86-0.98)$ respectively. The absolute difference divided

Table 1 Demographic, physical examination and blood pressure data of the study population

\begin{tabular}{ll}
\hline Variable & $\begin{array}{l}\text { Study population } \\
( \pm \text { SD })\end{array}$ \\
\hline Age & $63.08( \pm 11.54)$ \\
Male & $41 \%$ \\
Height & $1.71( \pm 0.09) \mathrm{m}$ \\
Weight & $86.56( \pm 15.02) \mathrm{kg}$ \\
Body mass index (BMI) & $29.52( \pm 4.35) \mathrm{kg} / \mathrm{m}^{2}$ \\
Body surface area (BSA) & $1.98( \pm 0.2) \mathrm{m}^{2}$ \\
$24 \mathrm{~h}$ average systolic & $128.94( \pm 10.75) \mathrm{mm} \mathrm{Hg}$ \\
blood pressure & \\
$24 \mathrm{~h}$ average diastolic & $74.42( \pm 8.26) \mathrm{mm} \mathrm{Hg}$ \\
blood pressure & \\
Smokers & $7.9 \%$ \\
Number of different & $1.57( \pm 1.15)$ \\
antihypertensive agents & \\
taken daily &
\end{tabular}

Table 2 Ultrasound data of the study population

\begin{tabular}{ll}
\hline Variable & Study population $( \pm \mathrm{SD})$ \\
\hline LV ejection fraction & $61.48( \pm 5.04) \%$ \\
LVEDd & $5.08( \pm 0.5) \mathrm{cm}$ \\
LV end-diastolic volume & $95.16( \pm 24.64) \mathrm{ml}$ \\
IVSDd & $1.05( \pm 0.12) \mathrm{cm}$ \\
PWDd & $0.91( \pm 0.1) \mathrm{cm}$ \\
Indexed LV mass & $92.76( \pm 19.7) \mathrm{g} / \mathrm{m}^{2}$ \\
LA diameter & $40.86( \pm 6.40) \mathrm{mm}$ \\
LA volume & $70.98( \pm 20.12) \mathrm{ml}$ \\
Indexed LA volume $(\mathrm{LAVI})$ & $35.80( \pm 9.64) \mathrm{ml} / \mathrm{m}^{2}$ \\
E/A ratio & $1.11( \pm 0.47)$ \\
Average septal e' & $7.92( \pm 0.57) \mathrm{cm} / \mathrm{s}$ \\
Average lateral e' & $9.87( \pm 2.87) \mathrm{cm} / \mathrm{s}$ \\
E/e' ratio & $8.68( \pm 2.89)$ \\
IVRT & $94.31( \pm 21.78) \mathrm{ms}$ \\
\hline
\end{tabular}

by the mean of two measurements for intraobserver variability of LA contractile, conduit and reservoir strains was $5.7 \%, 5.5 \%$ and $4.9 \%$ respectively. Intraclass correlation coefficients $(95 \% \mathrm{CI})$ for interobserver variability of LA contractile, conduit and reservoir strains were $0.89(0.75-0.96), 0.91 \quad(0.79-0.96)$ and 0.93 (0.82-0.97) respectively. The absolute difference divided by the mean of two measurements for interobserver variability of LA contractile, conduit and reservoir strains was $8.6 \%, 6.0 \%$ and $5.5 \%$ respectively. $2 \mathrm{D}$ strain parameters of LA are shown in Table 3. Table 4 shows comparison of contractile, conduit and reservoir strain data of our study population with normal values of healthy individuals according to metanalysis by Faraz Pathan [8].

Seventeen patients had no ultrasound signs of LV DD, 26 patients had one sign, 19 patients had two signs and only 1 patient had 3 ultrasound signs of LV DD, which allowed us to firmly diagnose LV DD according to the guidelines [12]. The single patient who had 3 signs of LV

Table 3 LA strain data of the study population

\begin{tabular}{ll}
\hline Variable & Study population $( \pm$ SD $)$ \\
\hline Mean contractile strain & $-14.14( \pm 5.83) \%$ \\
$4 \mathrm{CH}$ contractile strain & $-13.90( \pm 4.51) \%$ \\
$2 \mathrm{CH}$ contractile strain & $-14.39( \pm 9.19) \%$ \\
Mean conduit strain & $15.98( \pm 4.85) \%$ \\
$4 \mathrm{CH}$ conduit strain & $14.99( \pm 4.63) \%$ \\
$2 \mathrm{CH}$ conduit strain & $16.97( \pm 5.78) \%$ \\
Mean reservoir strain & $31.03( \pm 7.64) \%$ \\
$4 \mathrm{CH}$ reservoir strain & $28.89( \pm 7.30) \%$ \\
$2 \mathrm{CH}$ reservoir strain & $33.17( \pm 9.28) \%$ \\
\hline
\end{tabular}


Table 4 LA strain data compared with normal values in healthy individuals

\begin{tabular}{lll}
\hline Variable & Study population $(95 \% \mathrm{Cl})$ & $\begin{array}{l}\text { Normal values according to } \\
\text { metanalysis (95\% Cl) }[8]\end{array}$ \\
\hline Mean contractile strain & $-14.14(-15.61--12.67) \%$ & $17.4(16.0-19.0) \%$ \\
Mean conduit strain & $15.98(14.76-17.20) \%$ & $23.0(20.7-25.2) \%$ \\
Mean reservoir strain & $31.03(29.11-32.96) \%$ & $39.4 \%(38.0-40.8) \%$ \\
\hline
\end{tabular}

Contractile, conduit and reservoir strains in patients with mild hypertension and paroxysmal AF are lower compared to normal population

DD was excluded from further analysis, so we had three groups of patients with 0,1 or 2 signs, showing LV DD. The mean contractile, conduit and reservoir strain values are shown in Table 5. Figures 2, 3 and 4 show graphical comparison of 2D LA strain data between these groups. Contractile strain differences between the groups were not statistically significant, $p=0.367$. Conduit strain had statistically significant differences between groups. The group without any signs of LV DD had statistically significantly higher conduit strain $(p=0.016$ vs 1 sign of LV DD and $p=0.001$ vs 2 signs of LV DD). Reservoir strain also followed the same pattern as conduit strain with the group that had no signs of LV DD having statistically significantly higher reservoir strain values compared with other 2 groups ( $p=0.014$ vs 1 sign of LV DD and $p<0.001$ vs 2 signs of LV DD). Reservoir strain difference between groups with 1 and 2 signs of LV DD did not meet the cutoff of significance, $p=0.072$. We also checked for correlation of reservoir strain with average $E / \mathrm{e}^{\prime}$ ratio and found it to be statistically significant $(\mathrm{p}<0.001)$ with correlation coefficient -0.432 . Regression analysis and scatter plot are shown in Fig. 5.

\section{Discussion}

The method of 2D strain imaging for the evaluation of LA function is being extensively studied and its role in risk determination is constantly increasing. Ability to maintain sinus rhythm after cardioversion or pulmonary vein isolation, reverse atrial remodeling after AF ablation, outcomes in patients with coronary artery disease, exercise capacity in heart failure, development of AF in valvular heart disease, even embolic complications in patients with AF - all these can be predicted by LA strain analysis $[6,18]$. Though being so widely used and studied the method suffers from lack of standardization.

One of the main differences in the methodology is the reference point on the ECG. As most of the studies are done using GE software for LV strain analysis, the default setting is using ventricular cycle and zero reference point by default is set at the apex of $\mathrm{R}$ wave. Nevertheless, for the evaluation of atrial function using atrial cycle with zero reference point set at the start of $P$ wave generates negative contractile function strain which is more "physiological" than positive value obtained with $\mathrm{R}$ wave reference point. There are more studies done with $\mathrm{R}$ being the reference point but most of the experts, including European taskforce members, agree that the onset of the P wave should be used to analyze LA strain in sinus rhythm as we did in our study [19-21].

Of no less importance is the question which parts of LA wall to include in the strain analyses. Expert consensus document of EACVI and EHRA on the role of multi-modality imaging for the evaluation of patients with AF recommends LA strain imaging to be performed only in the lateral wall [19]. This way the influence of nearby structures such as aorta and right atrium can be diminished. Despite that, there have been different approaches in multiple studies from the evaluation of all the segments in 4, 3 and 2 chamber apical views to just 6 segments in 4 chamber apical view. Though methodologically probably the correct approach would be to evaluate all the walls of the LA from 3 apical views [20, 21], the meta-analysis done by Faraz Pathan et al. revealed that the results of the studies using four-chamber view only, four- and two-chamber views, and four-, two-, and three-chamber views were very similar: $38 \%$ (95\% CI, 35$41 \%$ ), $41 \%$ (95\% CI, 39-43\%), and 39\% (95\% CI, 31-47\%), respectively, and the difference was not statistically significant $(p=0.33)$ [8].

Our results show that all three LA functions are lower in patients with mild well treated arterial hypertension and paroxysmal AF compared with recently established normal values. These findings suggest that in hypertensive patients changes in the LA myocardium occur very early and support the role of LA strain imaging as an important and a very sensitive marker of hypertensive

Table $\mathbf{5}$ LA strain values of patients with 0,1 , or 2 signs of LV DD

\begin{tabular}{llll}
\hline & $\begin{array}{l}\text { Contractile strain } \\
\text { mean }( \pm \text { SD })\end{array}$ & $\begin{array}{l}\text { Conduit strain } \\
\text { mean }( \pm \text { SD })\end{array}$ & $\begin{array}{l}\text { Reservoir strain } \\
\text { mean }( \pm \text { SD) }\end{array}$ \\
\hline 0 signs of LV DD & $-15.68( \pm 6.73) \%$ & $18.87( \pm 4.44) \%$ & $35.82( \pm 6.93) \%$ \\
1 sign of LV DD & $-13.74( \pm 5.85) \%$ & $15.43( \pm 4.57) \%$ & $30.48( \pm 6.10) \%$ \\
2 signs of LV DD & $-12.96( \pm 4.80) \%$ & $13.72( \pm 4.30) \%$ & $26.68( \pm 7.68) \%$ \\
\hline
\end{tabular}

Strain values decrease as there are more signs of LV DD 


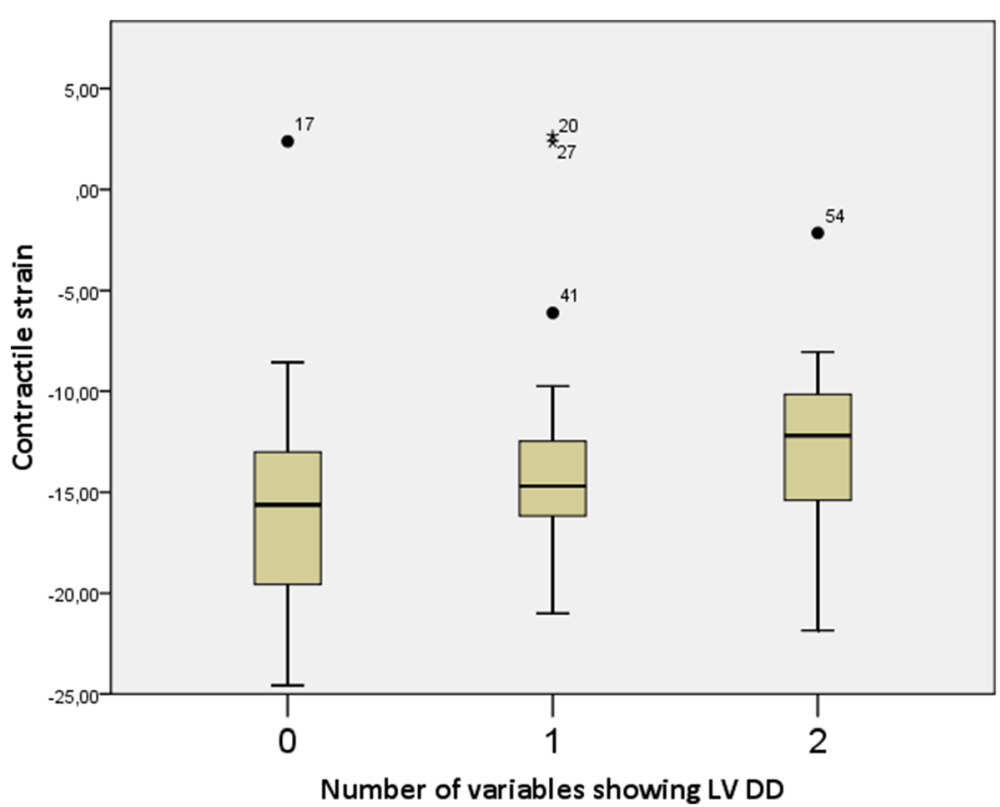

Fig. 2 Contractile strain comparison between groups with different number of LV DD signs. There was no significant difference between the groups, $p=0.367$

heart disease [22]. Recent data from Melissa Leung that links decreased LA reservoir strain with LA fibrosis, a fundamental component of hypertensive heart disease and $\mathrm{AF}$, makes it even more valid and relevant in these conditions [23].

The second part of our analysis aimed to determine how LA strain parameters change with increasing number of parameters showing LV DD. The relation of LA strain parameters with different LV DD grades has been studied before and it seems that strain parameters follow a distinct pattern with the decreasing LV diastolic function. It has been shown that the most sensitive parameters of LV DD are reservoir and conduit strains, which significantly decrease even in mild LV DD and

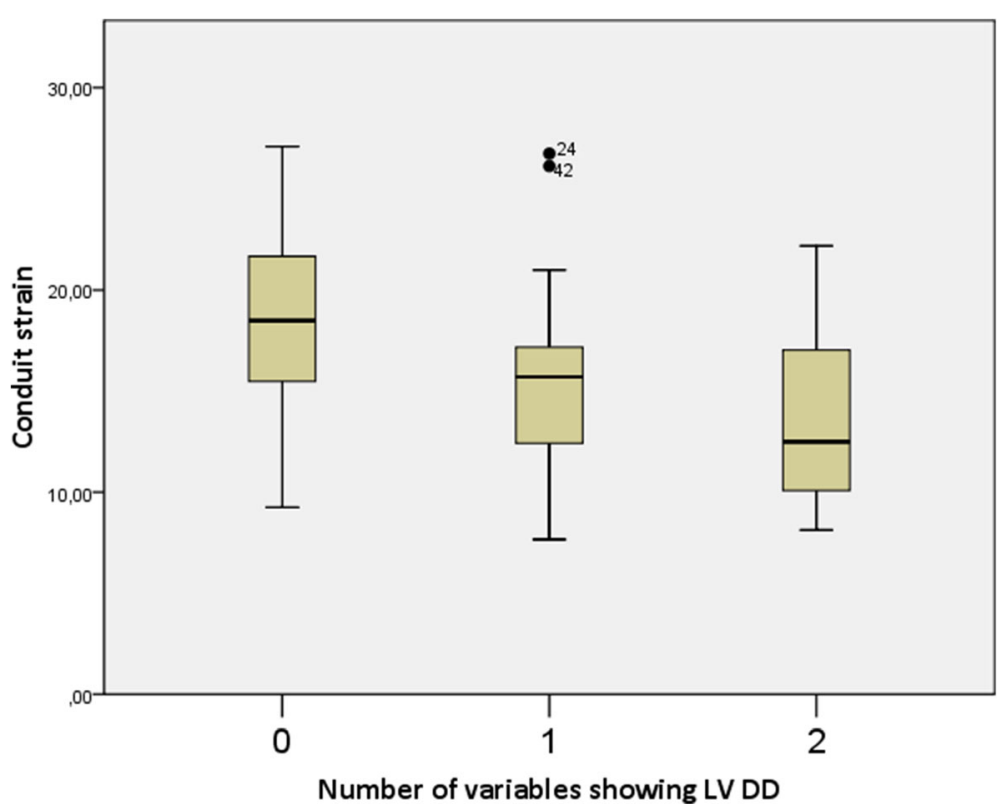

Fig. 3 Conduit strain comparison between groups with different number of LV DD signs. Group with no signs of LV DD had higher conduit strain values ( $p=0.016$ vs 1 sign of LV DD and $p=0.001$ vs 2 signs of LV DD). Difference between groups with 1 and 2 signs of LV DD were not statistically significant, $p=0.213$ 


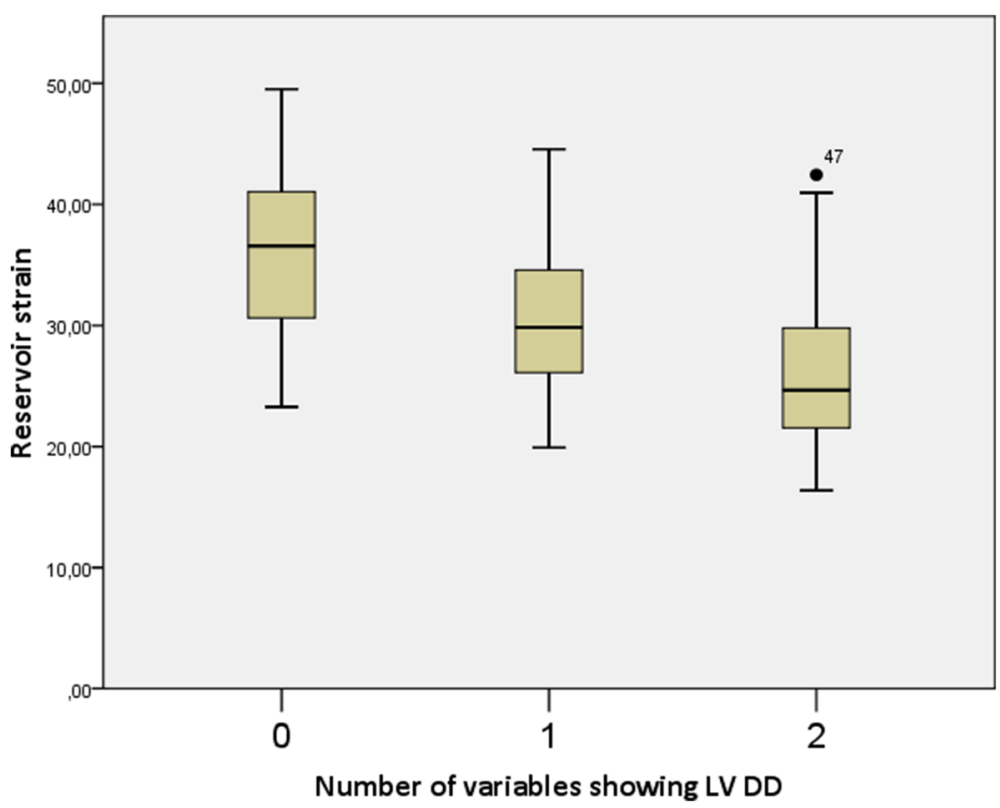

Fig. 4 Reservoir strain comparison between groups with different number of LV DD signs. Group with no signs of LV DD had higher reservoir strain values ( $p=0.014$ vs 1 sign of LV DD and $p<0.001$ vs 2 signs of LV DD). Difference between groups with 1 and 2 signs of LV DD did not meet the cutoff of significance, $p=0.072$

continue to decrease as the diastolic function gets worse. ROC curves show that diminished reservoir and conduit strains are superior even to LAVI in diagnosing early-stage LV DD. Meanwhile, contractile strain follows a different pattern. With mild LV DD LA contractility can even increase, dropping only when the DD is obvious $[24,25]$. This seems logical and can be explained as reservoir and conduit strains mostly depend on LV longitudinal contraction and LA myocardial compliance whereas contractile strain is mostly influenced by LA myocardial contractility and LV filling pressures [26].

Our results confirm this strain changing pattern with decreasing LV diastolic function with the addition that the LA strain changes precede traditional signs of LV

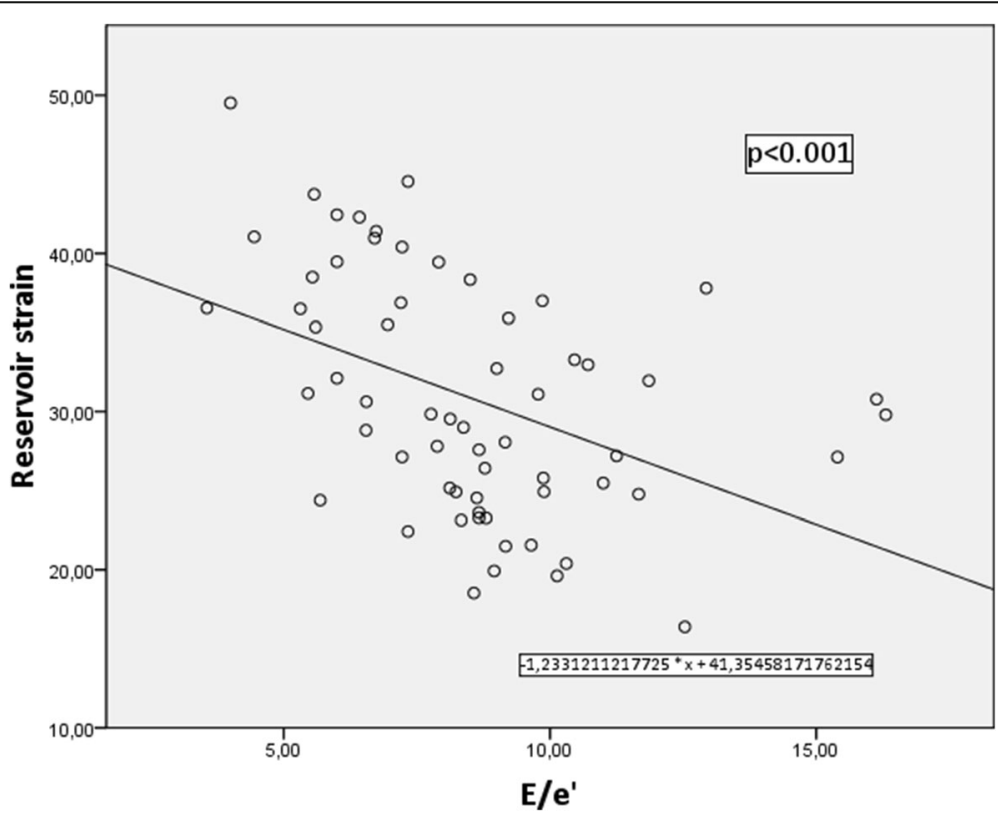

Fig. 5 Scatterplot showing relation between reservoir strain and E/e'. There is significant correlation between marker of LV DD E/e' and reservoir strain 
DD. Our patients were early in the course of developing DD as the majority of them had only 1 or 2 signs of LV DD which did not allow us to make an echocardiographic diagnosis of LV DD according to the guidelines [12] but they had already decreased LA strains. With increasing LV filling pressures and decreasing LV diastolic function reservoir and conduit strain values continuously decreased, while contractile strain values did not change or even increased, though it was not statistically significant.

If we followed the recently published guidelines on LV DD [12], only one patient in our study could be firmly diagnosed with LV DD. Significant part with decreased LA strains would fall into the indeterminate LV DD category. Probably this is the area where the LA strain parameters would be most helpful and could allow us to determine the risk of future cardiovascular events better.

\section{Conclusions}

The patients with paroxysmal atrial fibrillation and primary arterial hypertension have decreased all 3 - reservoir, conduit and pump - functions assessed by 2D strain imaging even in the absence of echocardiographic signs of increased LV filling pressures. With increasing number of parameters showing high LV filling pressures LA conduit and reservoir functions decrease while contractile does not change or even increase. LA conduit and reservoir functions decrease earlier than the diagnosis of LV DD can be established according to the current guidelines in patients with primary arterial hypertension and AF.

\section{Abbreviations \\ AF: Atrial fibrillation; Cl: Confidence intervals; DD: Diastolic dysfunction; EACVI: European Association of Cardiovascular Imaging; EHRA: European Heart Rhythm Association; LA: Left atrium; LV: Left ventricle; SD: Standard deviation}

\section{Acknowledgements}

Not applicable.

Funding

Not applicable.

\section{Availability of data and materials}

The datasets used and analyzed during the study are available from the corresponding author on request.

\footnotetext{
Authors' contributions

JJ contributed to acquisition, analysis and interpretation of the data, was a major contributor in writing the manuscript. AA and SA contributed to conception and design of the paper, analysis and interpretation of the data. All authors read and approved the final manuscript.
}

\section{Ethics approval and consent to participate}

The study has been approved by the appropriate ethics committees and has been performed in accordance with the ethical standards laid down in the 1964 Declaration of Helsinki and its later amendments. All persons gave their informed consent prior to their inclusion in the study.
Consent for publication

Not applicable.

\section{Competing interests}

The authors declare that they have no competing interest.

\section{Publisher's Note}

Springer Nature remains neutral with regard to jurisdictional claims in published maps and institutional affiliations.

Received: 6 August 2018 Accepted: 17 October 2018 Published online: 31 October 2018

\section{References}

1. Hoit BD. Left atrial size and function: role in prognosis. J Am Coll Cardiol. 2014;63(6):493-505.

2. Lip GY. Atrial fibrillation in patients with hypertension: trajectories of risk factors in yet another manifestation of hypertensive target organ damage. Hypertension. 2016;68:544-5.

3. Rosenberg MA, Manning WJ. Diastolic dysfunction and risk of atrial fibrillation: a mechanistic appraisal. Circulation. 2012 Nov 6;126(19):2353-62.

4. Williams B, Mancia G, Spiering W, Agabiti Rosei E, Azizi M, Burnier M, Clement DL, Coca A, de Simone G, Dominiczak A, Kahan T, Mahfoud F, Redon J, Ruilope L, Zanchetti A, Kerins M, Kjeldsen SE, Kreutz R, Laurent S, Lip GYH, McManus R, Narkiewicz K, Ruschitzka F, Schmieder RE, Shlyakhto E, Tsioufis C, Aboyans V, Desormais I. 2018 ESC/ESH Guidelines for the management of arterial hypertension. Eur Heart J. 2018;39(33):3021-104.

5. Obokata M, Negishi K, Kurosawa K, Tateno R, Tange S, Arai M, Amano M, Kurabayashi M. Left atrial strain provides incremental value for embolism risk stratification over $\mathrm{CHA}_{2} \mathrm{DS}_{2}$-VASC score and indicates prognostic impact in patients with atrial fibrillation. J Am Soc Echocardiogr. 2014;27:709-716.e4.

6. Leung M, van Rosendael PJ, Abou R, Ajmone Marsan N, Leung DY, Delgado V, Bax JJ. Left atrial function to identify patients with atrial fibrillation at high risk of stroke: new insights from a large registry. Eur Heart J. 2018 Apr 21;39(16):1416-25.

7. Galderisi M, Donal E, Magne J, Lo ludice F, Agricola E, Sade LE, Cameli M, Schwammenthal E, Cardim N, Cosyns B, Hagendorff A, Neskovic AN, Zamorano JL, Lancellotti P, Habib G, Edvardsen T, Popescu BA. Rationale and design of the EACVI AFib Echo Europe registry for assessing relationships of echocardiographic parameters with clinical thromboembolic and bleeding risk profile in non-valvular atrial fibrillation. Eur Heart J Cardiovasc Imaging. 2018 Mar 1;19(3):245-52.

8. Pathan F, D'Elia N, Nolan MT, et al. Normal ranges of left atrial strain by speckle-tracking echocardiography: a systematic review and meta-analysis. J Am Soc Echocardiogr. 2017;30:59-70.e8.

9. Xu TY, Sun JP, Lee AP, Yang XS, Ji L, Zhang Z, et al. Left atrial function as assessed by speckle-tracking echocardiography in hypertension. Medicine (Baltimore). 2015;94:e526.

10. Morris DA, Belyavskiy E, Aravind-Kumar R, Kropf M, Frydas A, Braunauer K, Marquez E, Krisper M, Lindhorst R, Osmanoglou E, Boldt LH, Blaschke F, Haverkamp W, Tschöpe C, Edelmann F, Pieske B, Pieske-Kraigher E. Potential Usefulness and Clinical relevance of adding left atrial strain to left atrial volume index in the detection of diastolic dysfunction diastolic dysfunction. JACC Cardiovasc Imaging. 2018;11(10):1405-15.

11. Degirmenci H, Duman H, Demirelli S, Bakirci EM, Hamur H, Inci S, Simsek Z, Askin L, Arisoy A, Lazoglu Z. Assessment of effect of irbesartan and nebivolol on the left atrium volume and deformation in the patients with mildmoderate hypertension. Eur Rev Med Pharmacol Sci. 2014;18(6):781-9.

12. Nagueh SF, Smiseth $O A$, Appleton CP, Byrd BF, Dokainish H, Edvardsen T, Flachskampf FA, Gillebert TC, Klein AL, Lancellotti P, Marino P, Oh JK, Popescu $B A$, Waggoner AD. Recommendations for the evaluation of left ventricular diastolic function by echocardiography: an update from the American Society of Echocardiography and the European Association of Cardiovascular Imaging. Eur Heart J Cardiovasc Imaging. 2016 Dec;17(12):1321-60.

13. O'Brien E, Parati G, Stergiou G, Asmar R, Beilin L, Bilo G, Clement D, de la Sierra A, de Leeuw P, Dolan E, Fagard R, Graves J, Head GA, Imai Y, Kario K, Lurbe E, Mallion JM, Mancia G, Mengden T, Myers M, Ogedegbe G, Ohkubo T, Omboni S, Palatini P, Redon J, Ruilope LM, Shennan A, Staessen JA, vanMontfrans G, Verdecchia P, Waeber B, Wang J, Zanchetti A, Zhang Y. European Society of Hypertension position paper on ambulatory blood pressure monitoring. J Hypertens. 2013;31:1731-68. 
14. Lang RM, Bierig M, Devereux RB, Flachskampf FA, Foster E, Pellikka PA, Picard MH, Roman MJ, Seward J, Shanewise J, Solomon S, Spencer KT, St John Sutton M, Stewart W. Recommendations for chamber quantification. Eur J Echocardiogr. $2006 \mathrm{Mar} ; 7(2): 79-108$.

15. Gottdiener JS, Bednarz J, Devereux R, Gardin J, Klein A, Manning WJ, Morehead A, Kitzman D, Oh J, Quinones M, Schiller NB, Stein JH, Weissman NJ. American Society of Echocardiography recommendations for use of echocardiography in clinical trials. J Am Soc Echocardiogr. 2004 Oct;17(10):1086-119.

16. Lang RM, Badano LP, Mor-Avi V, Afilalo J, Armstrong A, Ernande L, Flachskampf FA, Foster E, Goldstein SA, Kuznetsova T, Lancellotti P, Muraru D, Picard MH, Rietzschel ER, Rudski L, Spencer KT, Tsang W, Voigt JU. Recommendations for cardiac chamber quantification by echocardiography in adults: an update from the American Society of Echocardiography and the European Association of Cardiovascular Imaging. J Am Soc Echocardiogr 2015;28:1-39.e14.

17. Mor-Avi V, Lang RM, Badano LP, Belohlavek M, Cardim NM, Derumeaux G, Galderisi M, Marwick T, Nagueh SF, Sengupta PP, Sicari R, Smiseth OA, Smulevitz B, Takeuchi M, Thomas JD, Vannan M, Voigt JU, Zamorano JL. Current and evolving echocardiographic techniques for the quantitative evaluation of cardiac mechanics: ASE/EAE consensus statement on methodology and indications endorsed by the Japanese Society of Echocardiography. Eur J Echocardiogr. 2011 Mar;12(3):167-205.

18. Hoit BD. Evaluation of left atrial function: current status. Structural Heart 2017. https://doi.org/10.1080/24748706.2017.1353718.

19. Donal E, Lip GYH, Galderisi M, Goette A, Shah D, Marwan M, et al. EACVI/ EHRA expert consensus document on the role of multi-modality imaging for the evaluation of patients with atrial fibrillation. Eur Heart J Cardiovasc Imaging. 2016;17(4):355-83.

20. Rimbas RC, Dulgheru RE, Vinereanu D. Methodological gaps in left atrial function assessment by $2 \mathrm{D}$ speckle tracking echocardiography. Arq Bras Cardiol. 2015 Dec;105(6):625-36.

21. Hayashi S, Yamada H, Bando M, et al. Optimal analysis of left atrial strain by speckle tracking echocardiography: P-wave versus R-wave trigger. Echocardiography. 2015;32:1241-9.

22. De Simone G, Mancusi C, Esposito R, De Luca N, Galderisi M. Echocardiography in arterial hypertension. High Blood Press Cardiovasc Prev. 2018 Jun;25(2):159-66.

23. Leung M, Abou R, van Rosendael PJ, van der Bijl P, van Wijngaarden SE, Regeer MV, Podlesnikar T, Ajmone Marsan N, Leung DY, Delgado V, Bax JJ. Relation of echocardiographic markers of left atrial fibrosis to atrial fibrillation burden. Am J Cardiol. 2018 Aug 15;122(4):584-91.

24. Brecht A, Oertelt-Prigione S, Seeland U, Rucke M, Hattasch R, Wagelohner T, Regitz-Zagrosek V, Baumann G, Knebel F, Stangl V. Left atrial function in preclinical diastolic dysfunction: two-dimensional speckle-tracking echocardiography-derived results from the BEFRI trial. J Am Soc Echocardiogr. 2016 Aug;29(8):750-8.

25. Singh A, Addetia K, Maffessanti F, Mor-Avi V, Lang RM. LA strain for categorization of LV diastolic dysfunction. J Am Coll Cardiol Img. 2017;10:735-43.

26. Donal E, Behagel A, Feneon D. Value of left atrial strain: a highly promising field of investigation. Eur Heart J Cardiovasc Imaging. 2015;16:356-7.

Ready to submit your research? Choose BMC and benefit from:

- fast, convenient online submission

- thorough peer review by experienced researchers in your field

- rapid publication on acceptance

- support for research data, including large and complex data types

- gold Open Access which fosters wider collaboration and increased citations

- maximum visibility for your research: over $100 \mathrm{M}$ website views per year

At BMC, research is always in progress.

Learn more biomedcentral.com/submissions 